\title{
Can Shared Decision Making Help Eliminate Disparities in Rheumatoid Arthritis Outcomes?
}

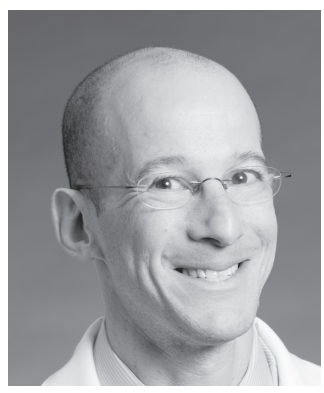

In this issue of The Journal, Barton, et al, publish a study on the quality of shared decision making between providers and patients with rheumatoid arthritis (RA) followed in 2 northern California cohorts ${ }^{1}$. Why is such a study important in what seems like a golden age of RA treatment? After all, there has been an explosion in RA treatment options and strategies, which has made remission a realistic target ${ }^{2}$. Earlier, more aggressive, and better treatment of RA has resulted in greatly improved outcomes compared to past decades $^{3}$. Barton, et al's study is not only important but timely, because not all have shared equally from the therapeutic benefits of the biologic era.

There is abundant evidence of racial and ethnic disparities in RA outcomes in the United States. Bruce, et al demonstrated that white patients with RA had less disability and better global health compared to nonwhite patients with $\mathrm{RA}^{4}$. Barton, et al reported lower disease activity and better functional status in whites, anglophones, and non-foreign-born patients in a university rheumatology clinic $^{5}$. Greenberg, et al recently published their findings from the Consortium of Rheumatology Researchers of North America RA registry showing that racial and ethnic disparities in disease activity and remission rates remained prevalent during the 2010-2012 time period ${ }^{6}$.

RA care disparities are neither limited to ethnic minorities nor restricted to the United States. Researchers in Sweden found that socioeconomic status and occupation influenced hospitalization rates for $\mathrm{RA}^{7}$, while patients in the United Kingdom from more deprived socioeconomic areas have been found to have a worse functional status than those from more affluent areas ${ }^{8}$. The multinational Quantitative Monitoring of Patients with Rheumatoid Arthritis (QUEST RA) cohort has also shown a negative association between disease activity and gross domestic product per capita ${ }^{9}$. The QUEST RA data also are remarkable for the less frequent achievement of remission in women compared to men ${ }^{10}$.
It is likely that some of the disparities seen in RA outcomes are related to inequity in medication use. Review of the Healthcare Effectiveness Data and Information Set showed that males, nonwhites, and persons of lower socioeconomic status were less likely to receive a disease-modifying antirheumatic drug (DMARD) ${ }^{11}$. The initiation of DMARD therapy is also often delayed in ethnic minorities ${ }^{12}$. Yelin, et al have recently published data revealing that the use of biologic therapies is affected by sociodemographic characteristics including income and ethnicity ${ }^{13}$.

Health literacy (HL) is another variable that may help explain systematic differences in medication use and disparities in RA care. HL has been defined as "the degree to which individuals can obtain, process, and understand the basic health information and services they need to make appropriate health decisions"14. A more nuanced conceptualization of health literacy focuses not only on the patient's skills, but also takes into account the demand side of the equation and the complexity of the healthcare system ${ }^{15}$. Nearly one-half of adults in the United States have limited $\mathrm{HL}^{16}$, and low HL is more prevalent among the elderly and ethnic minorities ${ }^{17}$.

Low HL is associated with poor health outcomes in many non-arthritic chronic diseases ${ }^{18}$. Similarly, RA patients with limited HL have worse functional status and wider discordance between provider and patient assessments of disease activity than patients with preserved $\mathrm{HL}^{19,20}$. A key next step in the HL RA research agenda is to define the mechanisms by which low HL affects RA outcomes.

There are several causal pathways by which limited HL might influence health outcomes: access and use of healthcare, patient-provider interaction, and self-care ${ }^{21}$. Our research at Denver Health has recently demonstrated that 1 in 4 patients at our safety-net public health clinic were unable to complete the visual analog scales used to

See Shared decision making in RA, page 1290

Personal non-commercial use only. The Journal of Rheumatology Copyright (c) 2014. All rights reserved. 
obtain common patient-reported outcomes such as the patient global assessment of disease activity and general health ${ }^{22}$. This research provides an example regarding how systemic factors make the use of healthcare challenging for those with low HL.

Barton, et al's publication in this issue of The Journal ${ }^{1}$ focuses on provider-patient communication, a salient factor that might mediate the relationship between low HL and RA outcomes. The researchers found that nearly one-third of subjects reported suboptimal shared decision making (SDM) communication. Low HL, lack of trust in physician, and limited English proficiency were all independently associated with poor SDM. These findings raise the question of how suboptimal SDM affects RA medication adherence and disease outcomes. The role of SDM in RA patients with low HL needs to be clarified given recent research in vulnerable patients demonstrating that unwillingness to take a DMARD ${ }^{23}$, and poor DMARD adherence ${ }^{24}$, are associated with risk perception and high medication concerns, respectively.

The emerging field of HL-related rheumatology research has clarified the HL skills of our patients, the readability of our written material, and the outcomes associated with limited HL. Barton, et al's study is an important contribution to the newest and most essential strand of HL research in rheumatology - how do we improve outcomes and eliminate disparities for RA patients with low HL? Little has been published to answer this question, with the exception of 1 study in which plain language information and individualized education failed to improve adherence and self-efficacy in patients with inflammatory arthritis 25 .

Wayne Gretzky famously remarked, "You miss 100 percent of the shots you never take." Fortunately rheumatologists are starting to take aim and fire at this vexing question. Exciting research is being conducted regarding potential interventions to improve shared decision making, including the design of an HL universal precautions toolkit for rheumatology $\mathrm{y}^{26}$, and the development of medication decisional aids ${ }^{27}$. Such research needs to be continued and supported until the most vulnerable patients in our societies are unrecognizable from the most affluent in terms of RA disease activity and functional status.

\section{JOEL M. HIRSH, MD,}

Denver Health and Hospital Authority, 777 Bannock St., Mail Code 4000 Denver, Colorado 80204, USA.

Address correspondence to Dr. J. Hirsh. E-mail: joel.hirshMD@dhha.org

\section{REFERENCES}

1. Barton JL, Trupin L, Tonner C, Imboden J, Katz P, Schillinger D, et al. English language proficiency, health literacy, and trust in physician are associated with shared decision making in rheumatoid arthritis. J Rheumatol 2014;41:xxxx.

2. Singh JA, Furst DE, Bharat A, Curtis JR, Kavanaugh AF, Kremer
JM, et al. 2012 update of the 2008 American College of Rheumatology recommendations for the use of disease-modifying antirheumatic drugs and biologic agents in the treatment of rheumatoid arthritis. Arthritis Care Res 2012;64:625-39.

3. Aga AB, Lie E, Uhlig T, Olsen IC, Wierod A, Kalstad S, et al. Time trends in disease activity, response and remission rates in rheumatoid arthritis during the past decade: results from the NOR-DMARD study 2000-2010. Ann Rheum Dis 2013 Nov 27 (E-pub ahead of print).

4. Bruce B, Fries JF, Murtagh KN. Health status disparities in ethnic minority patients with rheumatoid arthritis: a cross-sectional study. J Rheumatol 2007;34:1475-9.

5. Barton JL, Trupin L, Schillinger D, Gansky SA, Tonner C, Margaretten M, et al. Racial and ethnic disparities in disease activity and function among persons with rheumatoid arthritis from university-affiliated clinics. Arthritis Care Res 2011;63:1238-46.

6. Greenberg JD, Spruill TM, Shan Y, Reed G, Kremer JM, Potter J, et al. Racial and ethnic disparities in disease activity in patients with rheumatoid arthritis. Am J Med 2013;126:1089-98.

7. Li X, Sundquist J, Sundquist K. Socioeconomic and occupational risk factors for rheumatoid arthritis: a nationwide study based on hospitalizations in Sweden. J Rheumatol 2008;35:986-91.

8. Harrison MJ, Farragher TM, Clarke AM, Manning SC, Bunn DK, Symmons DP. Association of functional outcome with both personal- and area-level socioeconomic inequalities in patients with inflammatory polyarthritis. Arthritis Rheum 2009;61:1297-304.

9. Putrik P, Sokka T, Ramiro S, Boonen A. Impact of socioeconomic gradients within and between countries on health of patients with rheumatoid arthritis (RA): lessons from QUEST RA. Best Pract Res Clin Rheumatol 2012;26:705-20.

10. Sokka T, Toloza S, Cutolo M, Kautiainen H, Makinen H, Gogus F, et al. Women, men, and rheumatoid arthritis: analyses of disease activity, disease characteristics, and treatments in the QUEST-RA study. Arthritis Res Ther 2009;11:R7.

11. Schmajuk G, Trivedi AN, Solomon DH, Yelin E, Trupin L, Chakravarty EF, et al. Receipt of disease-modifying antirheumatic drugs among patients with rheumatoid arthritis in Medicare managed care plans. JAMA 2011;305:480-6.

12. Suarez-Almazor ME, Berrios-Rivera JP, Cox V, Janssen NM, Marcus DM, Sessoms S. Initiation of disease-modifying antirheumatic drug therapy in minority and disadvantaged patients with rheumatoid arthritis. J Rheumatol 2007;34:2400-7.

13. Yelin E, Tonner C, Kim SC, Katz JN, Ayanian JZ, Brookhart MA, et al. Sociodemographic, disease, health system, and contextual factors affecting the initiation of biologic agents in rheumatoid arthritis: A longitudinal study. Arthritis Care Res 2013 Dec 10 (E-pub ahead of print).

14. Ratzan SC, Parker RM. Introduction. In: Selden CR, Zorn M, Ratzan SC, Parker RM, eds. National Library of Medicine current bibliographies in medicine: health literacy. NLM Pub. No. CBM 2000-1. Bethesda, Maryland: National Institutes of Health, U.S. Department of Health and Human Services; 2000.

15. Rudd RE. Mismatch between skills of patients and tools in use: might literacy affect diagnoses and research? J Rheumatol 2010;37:885-6.

16. Kutner M, Greenberg E, Jin Y, Paulsen C. The health literacy of America's adults: results from the 2003 National Assessment of Adult Literacy (NCES 2006-483). U.S. Department of Education. Washington, DC: National Center for Education Statistics; 2006.

17. Paasche-Orlow MK, Parker RM, Gazmararian JA, Nielsen-Bohlman LT, and Rudd RR. The prevalence of limited health literacy. J Gen Intern Med 2005;20:175-84.

18. Berkman ND, Sheridan SL, Donahue KE, Halpern DJ, Crotty K. Low health literacy and health outcomes: an updated systematic review. Ann Intern Med 2011;155:97-107. 
19. Hirsh JM, Boyle DJ, Collier DH, Oxenfeld AJ, Caplan L. Health literacy predicts the discrepancy between patient and provider global assessments of rheumatoid arthritis activity at a public urban rheumatology clinic. J Rheumatol 2010;37:961-6.

20. Caplan L, Wolfe F, Michaud K, Quinzanos I, Hirsh JM. Strong association of health literacy with functional status among rheumatoid arthritis patients: a cross-sectional study. Arthritis Care Res 2014;66:508-14.

21. Paasche-Orlow MK, Wolf MS. The causal pathways linking health literacy to health outcomes. Am J Health Behav 2007;31 Suppl 1:S19-26.

22. Hirsh JM, Davis LA, Quinzanos I, Keniston A, Caplan L. Health literacy predicts discrepancies between traditional written patient assessments and verbally administered assessments in rheumatoid arthritis. J Rheumatol 2014;41:256-64.

23. Martin RW, McCallops K, Head AJ, Eggebeen AT, Birmingham JD, Tellinghuisen DJ. Influence of patient characteristics on perceived risks and willingness to take a proposed anti-rheumatic drug. BMC Med Inform Decis Mak 2013;13:89.
24. Spruill TM, Ogedegbe G, Harrold LR, Potter J, Scher JU, Rosenthal PB, et al. Association of medication beliefs and self-efficacy with adherence in urban Hispanic and African-American rheumatoid arthritis patients. Ann Rheum Dis 2014;73:317-8.

25. Rudd RE, Blanch DC, Gall V, Chibnik LB, Wright EA, Reichmann $\mathrm{W}$, et al. A randomized controlled trial of an intervention to reduce low literacy barriers in inflammatory arthritis management. Patient Educ Couns 2009;75:334-9.

26. Callahan LF, Hawk V, Rudd R, Hackney B, Bhandari S, Prizer LP, et al. Adaptation of the health literacy universal precautions toolkit for rheumatology and cardiology - applications for pharmacy professionals to improve self-management and outcomes in patients with chronic disease. Res Social Adm Pharm 2013;9:597-608.

27. Li LC, Adam PM, Backman CL, Lineker S, Jones CA, Lacaille D, et al. A proof-of-concept study of ANSWER, a web-based methotrexate decision aid for patients with rheumatoid arthritis. Arthritis Care Res 2014 Mar 12 (E-pub ahead of print).

J Rheumatol 2014;41:1257-9; doi:10.3899/jrheum.140479 